\title{
Effect of Moisture Content on Pollen Storage of Hevea Clone RRIM 600 and RRIT 251
}

\author{
Sayamol Kaewbunjong ${ }^{1}$ and Uraiwan Tongkaemkaew ${ }^{2 *}$ \\ 1. Songkhla Rubber Research Centre, Rubber Research Institute of Thailand, Songkhla 90110, Thailand \\ 2. Faculty of Technology and Community Development, Thaksin University, Phatthalung 93110, Thailand
}

\begin{abstract}
Non-synchronous flowering and low natural pollination make breeding between clones of Heveabrasiliensis difficult. Pollen storage in liquid nitrogen $\left(-196{ }^{\circ} \mathrm{C}\right)$ was an ideal strategy for long-term preservation for hybridization. This study were investigated pollen viability of clone RRIM 600 and RRIT 251 after long storage in liquid nitrogen. Anther of both rubber clone were dried to $7 \%$ and $11 \%$ of moisture content levels before storage in liquid nitrogen. Pollen viability was testing by in-vitro germination in solution media and 2, 3, 5-triphenyl-tetrazolium-chloridestained. The results showed the moisture content at $11 \%$ storage 180 days were found pollen stained and pollen germination higher than at $7 \%$ of moisture content. This were the pollen stained $2.00 \%$ in clone RRIM 600 and $2.06 \%$ in clone RRIT 251 while pollen germination were $1.31 \%$ in clone RRIM 600 and 1.38\% in clone RRIT. Besides, the pollen storage for 90 days in both moisture contents having correlated to the duration of Hevea flowering period were found pollen viability more than $10 \%$. This finding will be the base information on the utilization of breeders for hybridization of Hevea varieties.
\end{abstract}

Key words: Heveabrasiliensis, rubber tree, liquid nitrogen, pollen viability, pollen germination.

\section{Introduction}

Rubber (Heveabrasiliensis) is a monoecious species with male, female, and bisexual flowers. The flowering is synchronously that correspond closely with solar radiation intensity. Flowering is occurs annually, although in some locations there can be minor secondary flowering. Thailand, rubber has synchronous flowering related factors in various localities of rubber cultivation, normally flowing months in main season were March. September to October were the secondary season. The district dry spell preceding flowing were found in main season. Dry season or the transition from the dry to the wet season are relevant factors that may accentuate flowing in Hevea, they are not primarily responsible for the induction of synchronous flowing. The conditions influence to rubber trees non-synchronous flowering.

\footnotetext{
*Corresponding author: Uraiwan Tongkaemkaew, Ph.D., research fields: plant physiology, farming system and green rubber. E-mail: t_uraiwan@hotmail.com.
}

Hybridization, rubber breeding has experienced in different varieties of species. The previous studies showed pollen germination in a large number clones in testing on artificial media were found low germination particular in room temperature condition. This is the complicated for breeders on the rubber hybridization. In other contexts, pollen may be stored for germplasm conservation, to make hybrids between plants that flower at different times or places, or for later use in hybridization programmes, and the quality must be monitored [1-3].

Pollen viability is important in agriculture and for plant breeders since pollen must be viable at the time of pollination for seed (or fruit) set to occur. Pollen's living, behaviour and survival are influenced by both environment and genotype. In addition, pollen grains are present in anthers and show undifferentiated or grossly shrunken grains. Most pollen samples will have a few such inviable grains, but the presence of many aborted grains indicates substantial infertility. Assessment of pollen viability is critical for the study of the following aspects of pollination biology [1, 2, 4-6]. 
Pollen staining tests by FCR (Fluorochromatic reaction) test and 1, 2, 3-TTC (Triphenyl tetrazolium chloride) are among the best and most widely used tests of pollen viability $[7,8]$. Both tests are principally the integrity of the vegetative cell plasma membrane and rely on the presence of a non-specific esterase in the pollen cytoplasm. Pollen germination tests is able to germinate and produce a pollen tube, there is a high chance that it is viable and able to fertilize. Hence, for pollens where germination is possible in vitro. The vitro germination of pollen is widely used for viability tests, under the generally correct assumption that pollen that germinates and produces a tube in vitro is likely to do so in vivo, and to fertilize the egg. Pollen grains from many species will germinate and grow on both solid and liquid artificial media [9-13]. The most widely used media are modifications of the minimal medium of Brewbaker and Kwack [9] consisting of 1 to $4 \mathrm{mM} \mathrm{H}_{3} \mathrm{BO}_{3}$ and 1 to $4 \mathrm{mM} \mathrm{Ca}\left(\mathrm{NO}_{3}\right)_{2}$ in 0.30 to $0.90 \mathrm{M}(10-30 \%$ sucrose). Boron and calcium are often the only essential elements, although various workers add magnesium, phosphate buffers, flavenols, and non-specific substances[5, 8, 9].

Rubber has reported that the maintaining of pollen viability for a long period is important in rubber breeding. The preservation of pollen grain storage in the liquid nitrogen $\left(-196^{\circ} \mathrm{C}\right)$ was mentioned an ideal strategy for long-term preservation for hybridization [10]. However, pollen moisture content has important condition for long storage as well. Hamzahand Leene [10] showed rubber pollen storage by reduced moisture content level from $7 \%$ to $11 \%$ before storage in liquid nitrogen for 5 months; the pollen were remain long preserved 1 month with the ability of fertilization 6\% in the laboratory testing. Only one fruit was obtained in another crossing of 330 flowers. This study were conducted reducing moisture content (RMC) at 7\% and $11 \%$ of pollen Hevea clone RRIM 600 and RRIT 251 before storage in liquid nitrogen. The stored period pollen was assessed for viability using the in vitro germination and staining.

\section{Materials and Methods}

Male flowers of rubber clone RRIT 251 and RRIM 600 were carried out two hours to laboratory to reduce moisture content. Then, pollen moisture content was reduce occurred $7 \%$ and $11 \%$ at $25{ }^{\circ} \mathrm{C}$ by using Silica gel, whole flowers then stored in liquid nitrogen $\left(-196^{\circ} \mathrm{C}\right)$. Pollen was stained with either 1,2,3-triphenyl tetrazolium chloride (TTC) (10\% by weight in $50 \%$ sucrose) or iodine \pm potassium iodide (IKI) [5]. Pollen germination was cultured in solution standard media [9] with the modified sucrose $20 \%$ containing. Pollen staining and pollen culture were conducted at $0,5,10$, 15, 20, 25, 30, 45, 60, 75, 90, 105, 120, 135, 150, 165 and 180 DAS (day after stored). The solution media were use hanging drop to the hollow slides 3 drops. Five flowers in a replication and four replications were used for pollen viability. Anthers were pull out from flowers and smeared for rupture pollen out with the end of needle hand on a slide glasses. Then, pollen culture were incubated at room temperature and dark conditions and, pollen staining as done by parallel. Pollen germination were recorded after $24 \mathrm{~h}$ incubation. Pollen grains were considered to be germinated when the pollen tube length was greater than the diameter of the pollen grain [6]. Percentage of pollen germination was calculated by number of pollen gains germinated divided with the total of pollen gains (germination and non-germination). Beside, percentage of pollen gains stained were calculated by number of pollen stained divided with the total of pollen gains (stained and non-stained). Pollen germination and pollen stained observations were viewed under fluorescence microscopy.

\section{Results and Discussion}

The feature of pollen stained of Hevea, pollen quality were assessed first to find fertility, to monitor pollen state during storage (180 days). Nonaborted pollen or fertility were red stained, and pollen aborted or infertile were not stained by TTC (Fig. 1).

The observation of pollen viability of clone RRI 251 
and RRI 600 with RMC 7\% and 11\% before storage were not different by staining and in vitro. Rubber clone RRIT 251 has high staining and germination in 5 days storage. The pollen stained with RMC 7\% and 11\% obtained were $24.3 \%$ and $26.8 \%$ alike with pollen germination were found $21.6 \%$ and $22.9 \%$. Then,

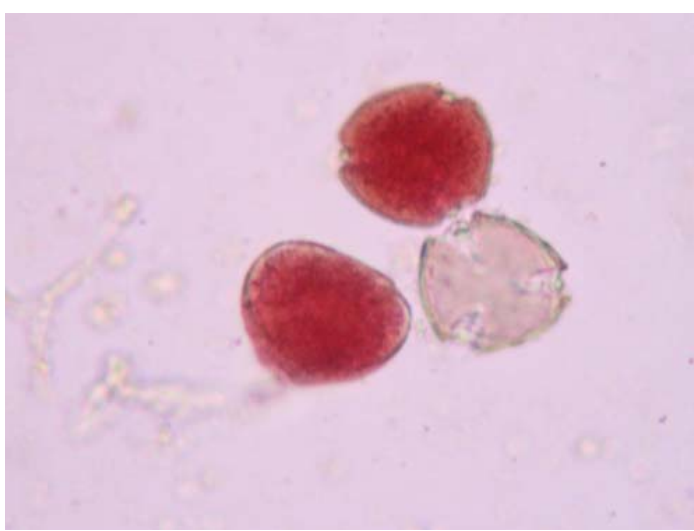

(a) percentage of both viability testing were constantly declined to the last day storage (Fig. 2).

Corresponding to rubber clone RRIT 600 were found. The pollen viability with RMC $7 \%$ and $11 \%$ before storage were obtained that the percent of pollen stained declined from initial day to the last day storage were

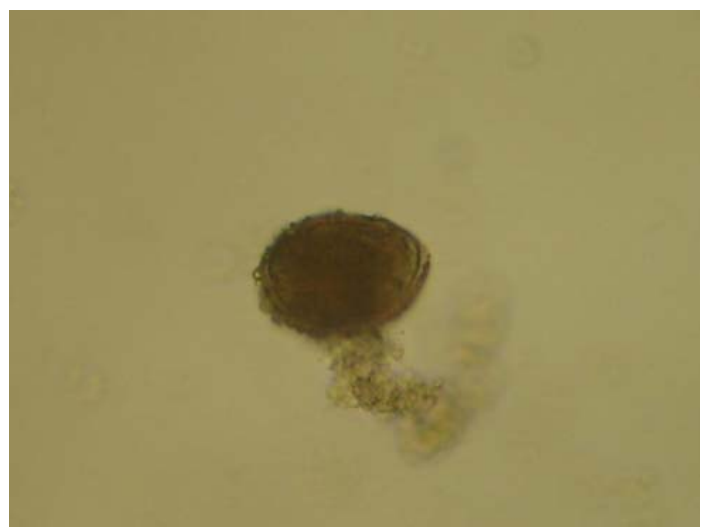

(b)

Fig. 1 The pollen stained (a) and pollen germination (b) of pollen Hevea samples.

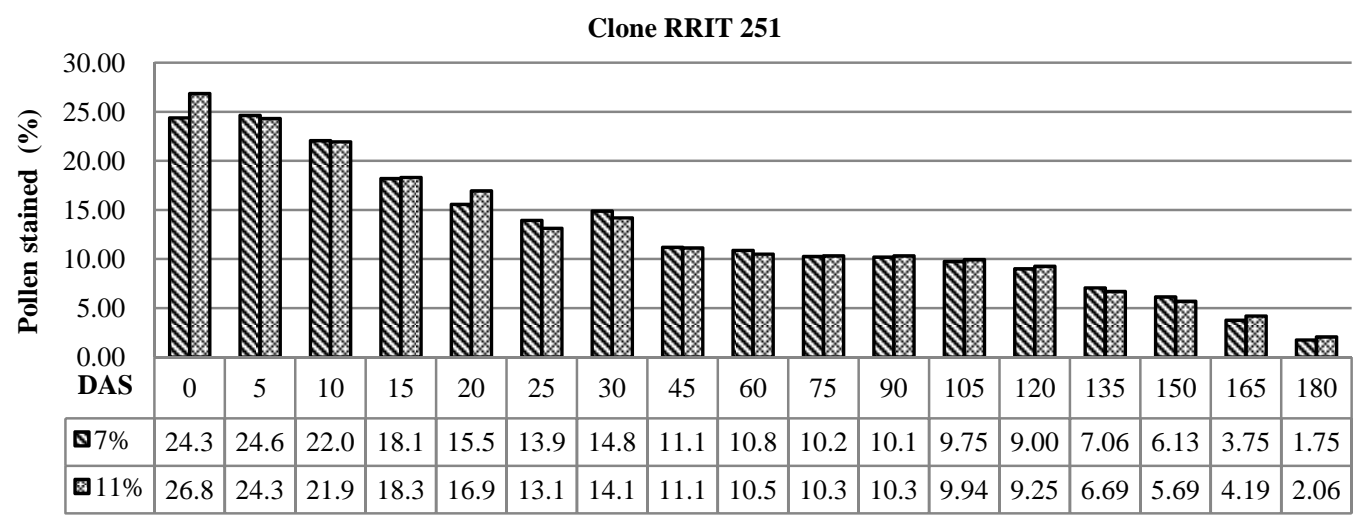

(a)

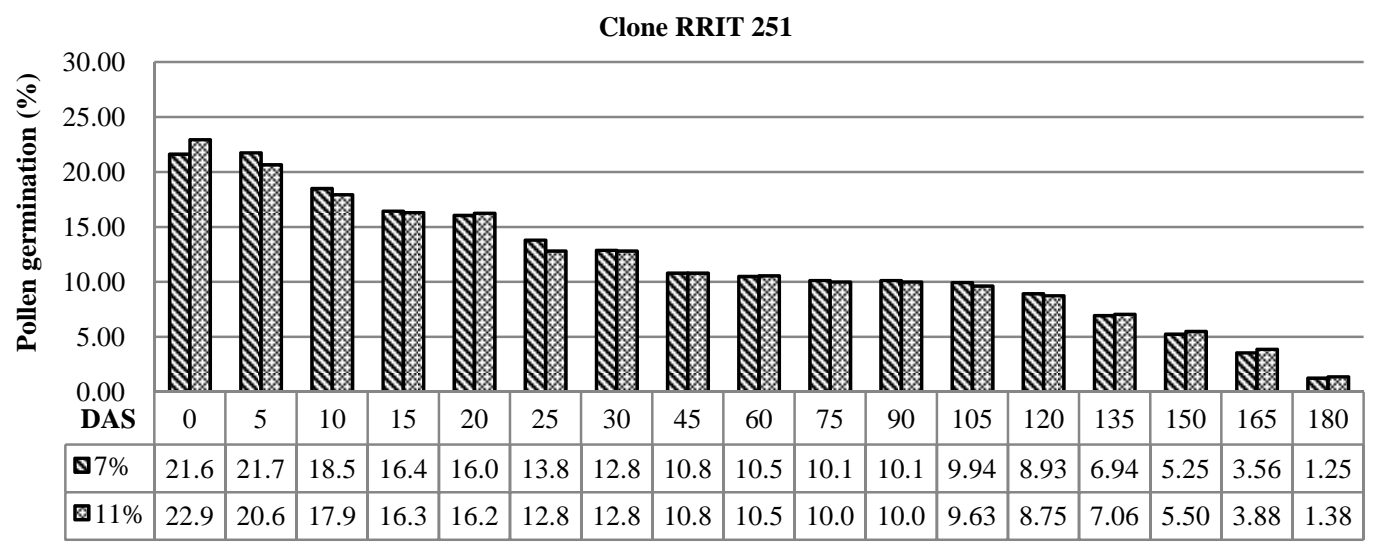

(b)

Fig. 2 Percentage of pollen stained (a) and pollen germination (b) with RMC at 7\% and 11\% of RRIT 251 long storage (180 days). 


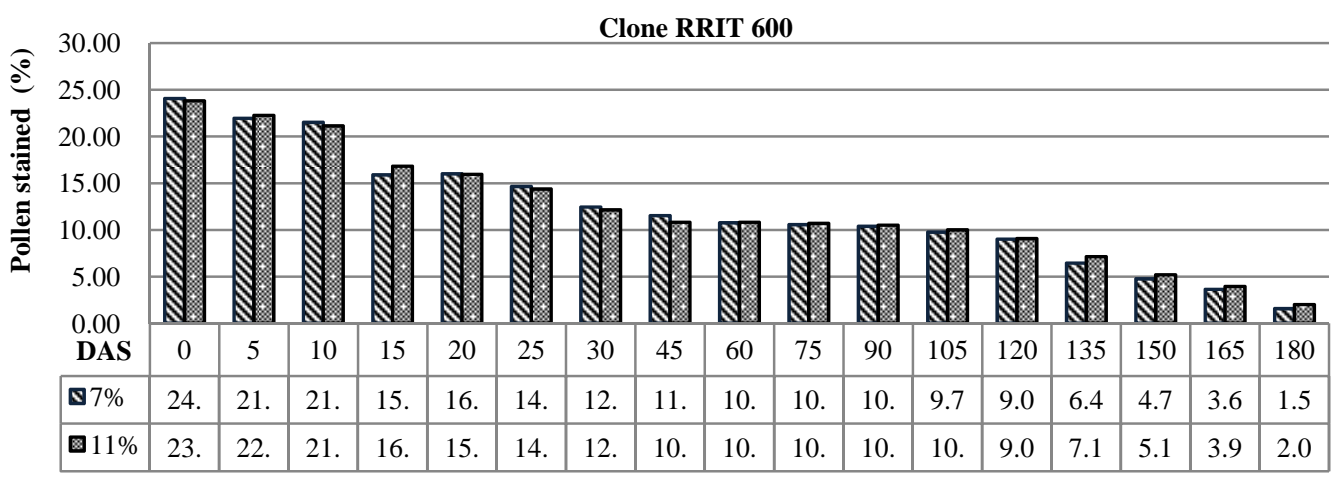

(a)

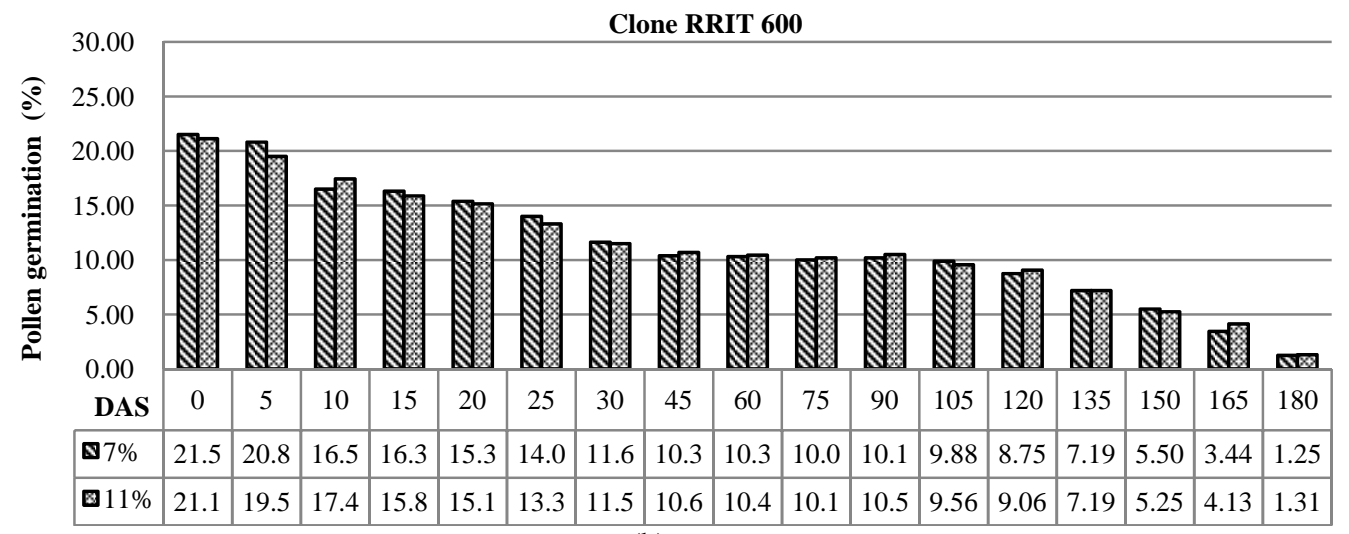

(b)

Fig. 3 Percentage of pollen stained (a) and pollen germination (b) with RMC at $7 \%$ and $11 \%$ of RRIM60 long storage (180 days).

found $24.06 \%$ to $1.56 \%$ and $23.81 \%$ to $2.00 \%$ (Fig. 3a). This like the percentage of pollen germination were constantly declined from the fifth day to the last day storage (Fig. 3b). No significant on pollen stained and pollen germination in the both moisture contents and the time of storage even between clone. From the results, show both of rubber clones were found very small pollen germination in long storage which impossible to use for hybridization in next season.

Rubber clone, however, when compared pollen viability of clone RRIT 251 and RRIT 600 found that; clone RRIT 600 was higher pollen viability than clone RRI 251 in the both moisture contents. While the level of RMC at $11 \%$ in the final day storage were showed percentage of pollen stained and pollen germination higher than RMC at 7\%. This study showed the pollen viability at 30 days after storage were consistent to the study of Hamzahand Leene [10] showed rubber pollen storage by reduction of moisture content level from 7 to $11 \%$ before storage in liquid nitrogen for 5 months; the pollen remain long preserved 1 month with the ability of fertilization $6 \%$ in the laboratory testing. Both of moisture contents were optimum to hold pollen in liquid nitrogen. However, when considerate to flowering period and pollen viability after storage of both clones found; pollen has viability around $10 \%$ in two moisture contents. The pollen storage at 30 days would be used suitable for breeding of Hevea species by hand pollination within the same season. This testing pollen quality will proved valuable for research on hybridization and give unique information about pollen fertility in two clone.

\section{Conclusions}

Non-synchronous flowering in Hevea and low pollen viability are the problems for hybridization. The study aim to investigate the pollen viability as moisture content reduced at $7 \%$ and $11 \%$ before storage in liquid 
nitrogen of clone RRIM 600 and RRIT 251 which is the commercial verities in Thailand. The studied were finding, no significant of moister content on the pollen germination and pollen stained. RRIM 600 and RRIT 251 clone were found high pollen viability in the incunabulum day storage. The pollen storage for 90 days was pollen germination around $10 \%$ would suitable for breeding by hand pollination within the flowering season.

\section{Acknowledgments}

This research was funded by Rubber Research Institute of Thailand. Thanks the office of agricultural research and development, Songkhla province where supported the laboratory. Special thanks are expressed to the rubber plantation owners who are well feeling to provide the plant material experiment.

\section{References}

[1] Dafni, A. and Firmage, D. 1999. "Pollen Viability and Longevity: Practical, Ecological and Evolutionary Implications, Pollen and Pollination.” Springer-Wien New York 113-130.

[2] Heslop-Hrrison, J. S. 1992. "Cytological Techniques to Assess Pollen Quality, Sexual Plant Reproduction.” Springer-Berlin 81-8.

[3] Yeang, H. Y. 2007. "Synchronous Flowering of the Rubber Tree (Heveabrasiliensis) Induced by High Solar
Radiation Intensity.” New Phytologist 175: 283-9.

[4] Hamzah, S., Chan, J. L. and Yeang, H. Y. 2002. "Pollen Tube Growth and Fruit-Set Success in Heveabrasilliensis Hand-Pollination Influenced by the Choice of Clone and Female Flower." Euphytica 123: 1-8.

[5] Ekkaratne, S. N. R. and Senathrirajah, S. 1983. "Viability and Storage of Pollen of the Oil Palm, ElaeisguineensisJacq.” Annals of Botany 51: 661-8.

[6] Dafni, A. 2000. "A New Procedure to Assess Pollen Viability.” Sexual Plant 12: 241-4.

[7] Mulugeta, D., Maxwell, B. D., Fay, P. K. and Dyer, W. E. 1994. "Kochia (Kochiascoparia) Pollen Dispersion, Viability and Germination.” Weed Science 42: 548-552.

[8] Li, J.,Nianijun, T., Fadi, C., Sumei, C., Chunqing, S. and Weimin, F. 2009. "Reproductive Characteristics of Opisthopappustaihngensis (Ling) Shih, an Endangered Asteraceae Species Endemic to China.” Scientia Horticulturae 121: 474-9.

[9] Brewbaker, J. L. and Kwack, B. H. 1963. “The Essential Role of Calcium Ion in Pollen Germination and Pollen Tube Growth.” American Journal of Botany 50: 747-858.

[10] Hamzah, S. and Leene, C. J. 1996. "Short Communication Pollen Storage of Hevea." Journal of Natural Rubber Research 11 (2): 115-124.

[11] Zhang, L. X., Chang, W. C., Wei, Y. J., Liu, L. and Wang, Y. P. 1993. "Cryopreservation of Ginseng Pollens.” Hort Science 28 (7): 742-3.

[12] Ganeshan, S. 1985. "Cryogenic Preservation of Grape (Vitisvinifera L.).” Vitis 24: 169-73.

[13] Ganeshan, S. and Alexander, M. P. 1990. "Fertilizing Ability of Cryopreserved Grape (Vitisvininfera L.) pollen.” Vitis 29: 145-50. 